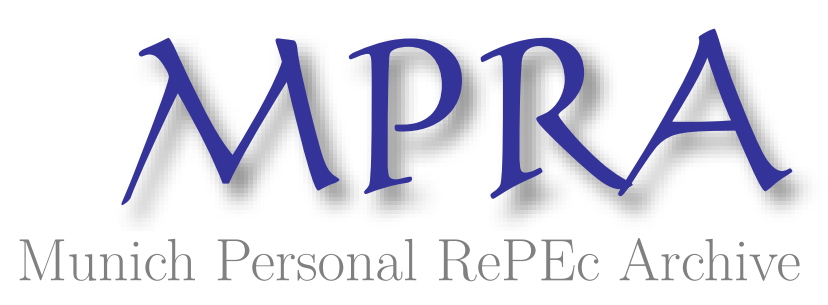

\title{
Price volatility and risk exposure: on the interaction of quota and product markets
}

Baldursson, Fridrik M. and Fehr, Nils-Henrik M. von der

Reykjavik University Institute for Research in Finance and

Economics, Department of Economics, University of Oslo

April 2009

Online at https://mpra.ub.uni-muenchen.de/14994/

MPRA Paper No. 14994, posted 04 May 2009 01:16 UTC 


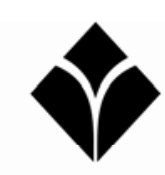

REYKJAVÍK UNIVERSITY

HÁSKÓLINNI REYKJAVÍK

\title{
RU Institute for Research in Finance and Economics
}

\author{
Working Papers
}

2009-04

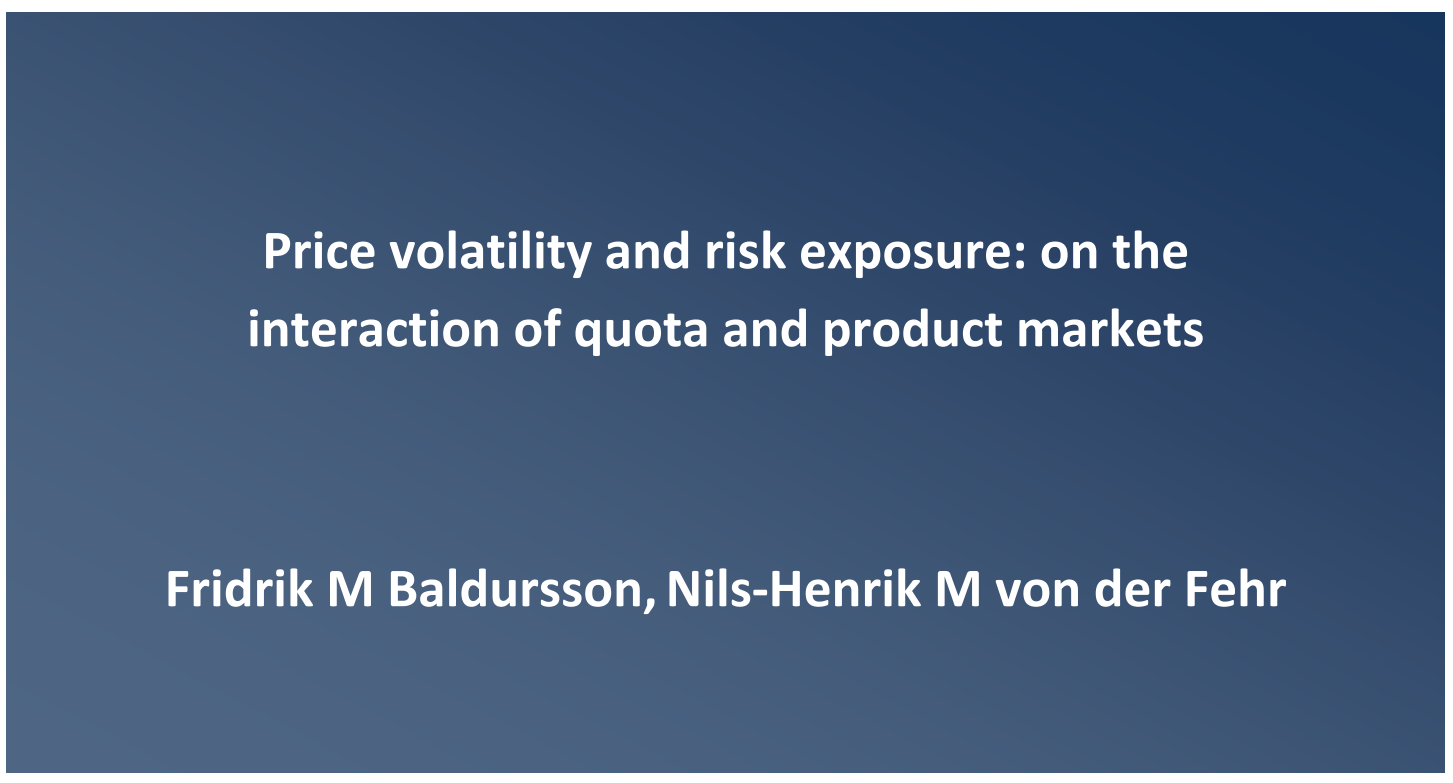

RU Institute for Research in Finance and Economics - School of Business - Reykjavik University - www.ru.is ISSN: $1670-7648$ 


\title{
Price volatility and risk exposure: on the interaction of quota and product markets
}

\author{
Fridrik M Baldursson \\ Reykjavik University (mb@ru.is) \\ Nils-Henrik M von der Fehr \\ University of Oslo (hhfehr@econ.uio.no)
}

April 22, 2009

\begin{abstract}
We consider an industry with firms that produce a final good emitting pollution to different degree as a side effect. Pollution is regulated by a tradable quota system where some quotas may have been allocated at the outset, i.e. before the quota market is opened. We study how volatility in quota price affects firm behaviour, taking into account the impact of quota price on final-good price. The impact on the individual firm differs depending on how polluting it is - whether it is 'clean' or 'dirty'- and whether it has been allocated quotas at the outset. In the absence of long-term or forward contracting, the optimal initial quota allocation turns out to resemble a grandfathering regime: clean firms are allocated no quotas - dirty firms are allocated quotas for a part of their emissions. With forward contracts and in the absence of wealth effects initial quota allocation has no effect on firm behaviour.
\end{abstract}

Keywords: regulation, effluent taxes, tradable quotas, uncertainty, risk aversion, environmental management

JEL Classification codes: D81, D9, H23, L51, Q28, Q38

Acknowledgements: We are grateful to seminar audiences at UCEI Summer Camp 2008 in Berkeley, NORIO 2008 at Copenhagen Business School, NEECI Annual Meeting 2008 at Helsinki School of Economics, Bocconi University, University of Groningen and University of Oslo for useful comments on earlier versions of this paper. 
"If one wants a price, that would seem strongly to suggest that a tax is going to work better than cap and trade, at least on the evidence that we have seen in the European system, where the prices that are set are extremely volatile." Martin Wolf, Financial Times Climate Change supplement, December 2, 2008.

\section{Introduction}

Market-based environmental regulation often exposes market participants to risk. In order to fully understand the implications of such risk it is important to take account of effects in other, related markets; for example, volatility of emission permit prices may translate into volatility of product prices. The purpose of this paper is to study how risk induced by environmental regulation affects behaviour when interaction between emissions prices and product prices is taken into consideration.

That environmental regulation may expose market participants to risk has been amply demonstrated by price developments in the European Emissions Trading Scheme (ETS). ${ }^{1}$ Prices of ETS allowances for $\mathrm{CO}_{2}$ emissions have fluctuated in a wide range - from virtually nil to over 30 Euro per tonne $\mathrm{CO}_{2}$ - and with abrupt changes - in the spring of 2006 prices fell from above 30 to below 10 Euros in less than two weeks. ${ }^{2}$ Price volatility of such a magnitude, for an input that for many firms constitutes a significant part of total costs, is likely to influence behaviour.

In Baldursson and von der Fehr (2004a), we studied how quota-price uncertainty affects the choice between alternative methods of controlling emissions. We found that firms, in order to reduce exposure to risk, behave differently from what they would have done had risk not been a concern. We demonstrated that aversion to risk has implications for how to design a permit market that promotes efficiency - including how to allocate quotas and whether to introduce opportunities for forward trading - as well as for the choice between a regulatory set up based on quotas and one based on price (i.e. an emissions tax).

That analysis was essentially limited to how quota-price volatility affects firms' costs. However, it is clear that volatility in quota prices may be transmitted to product markets and hence that, in order to analyse the overall implications of price volatility in quota markets, product markets may have

\footnotetext{
${ }^{1}$ Prices and other information on EUA quarterly futures contracts are reported by the European Climate Exchange (www.europeanclimateexchange.com).

${ }^{2}$ The fall in prices occured as it became clear that authorities had allocated more quotas than expected by market participants.
} 
to be included also. For example, Green (2008) points out that volatile fuel prices affect both the cost and price of electricity in a liberalised market, that generators with the price-setting technology will face less risk to their profit margins than those with costs that are not correlated with price, even if those costs are not volatile, and that emissions permit prices may respond to relative fuel prices, further increasing volatility. ${ }^{3}$ He simulates the impact of this on generators' profits, comparing an emissions trading scheme and a carbon tax against predictions for the UK in 2020.

In this paper, we extend the analysis in Baldursson and von der Fehr (2004a) to incorporate the interaction between product and quota markets. Unlike Green (2008), who aims to capture the institutional and technological characteristics of a particular market, we base our analysis on a general set up. This allows us to study in more detail the mechanisms at work, as well as how market outcomes depend on institutional and technological characteristics and regulatory policy.

Our paper contributes to two strands of economic literature: that on market-based environmental regulation under uncertainty and that on decisions of risk-averse firms. Our starting point is the observation by Weitzman (1974) and others that controlling the quantity of emissions by quotas makes the marginal cost of emissions reductions uncertain. This implies that marginal benefits and costs are not equalised. Unlike Weitzman and much of the subsequent literature, we analyse how the exposure to such uncertainty impacts on the behavior of market participants. ${ }^{4}$ We demonstrate that taking account of behavioural effects has implications also for the comparison of alternative market-based instruments - viz. taxes and quotas - an essential topic in this literature. ${ }^{5}$

\footnotetext{
${ }^{3}$ Newbery (2008) demonstrates how the ETS, through the interaction between fuel, quota and product markets, enhances the market power of gas suppliers, thereby amplifying the impact of gas price increases on the electricity price; he argues that a tax on $\mathrm{CO}_{2}$ emissions would not have such an effect and so would be preferable. We abstract from market power.

${ }^{4}$ Risk or uncertainty may also impact on behaviour when decisions are irreversible even when agents do not care about risk as such, an aspect that is ignored in our essentially static set up. This topic was treated by Chao and Wilson (1993), Dixit and Pindyck (1994), Baldursson and von der Fehr (2004b) and Zhao (2003); see also Xepapadeas (1999)

${ }^{5}$ Weitzman (1974) studied the costs and benefits of taxes and quotas in a static set up in which some amount of a particular good can be produced at a given cost, yielding welldefined benefits and showed that a quantity control performs better than a price control if and only if the marginal benefit curve is steeper than the marginal cost curve. Part of Weitzman's insight went back to Lerner (1971) and Upton (1971) and was formalised independently by a number of other authors, including Adar and Griffin (1976), Fishelson (1976) and Roberts and Spence (1976). This literature was surveyed by Yohe (1977, 1978). An exposition is given in Baumol and Oates (1988), while more recent contributions
} 
The study of risk-averse firms goes back to Magnusson (1969), Baron (1970) and Sandmo (1971), who mainly concentrated their attention on risk transmitted through the output price or demand for the product. ${ }^{6}$ An exception in this literature is Pindyck (1982), who considers how uncertainty about demand and costs affects investment of a single risk-averse firm; in his model, fluctuations in both input and output markets are exogenously given. Of particular relevance for our analysis is Viaene and Zilcha (1998), who examine the behaviour of a competitive risk-averse export firm subject to (possibly diversifiable) exchange rate and commodity price uncertainty, as well as to (non-diversifiable) background uncertainty arising from cost and production; however, they do not consider market equilibrium, nor do they model the interaction between input and output markets.

As in the earlier literature on risk-averse firms, and as argued in more detail by Varian (1990), we consider the assumption of risk aversion merely as a convenient reduced-form description of firms' behaviour under uncertainty. ${ }^{7}$ It is commonly observed that even firms owned by well-diversified stockholders take costly actions to reduce risk, including taking out insurance, dealing in forward contracts, diversifying operations across industries and so on. One reason may be that they are run by managers who are themselves inherently risk averse and whose compensation schemes may result in their utility being a concave function of profits. ${ }^{8}$ We extend the literature on risk-averse firms by considering risk originating from the input rather than the output side and by allowing for the twin exposure of input and output risk, where risk on the output side arises endogenously through the interaction of input and output markets.

We start our analysis by considering a competitive industry in which risk-averse firms produce a certain good; production has the side effect of

include Stavins (1996) and Montero (2002). Meyer (1984) demonstrates that the relative performance of price and quantity controls depends on whether agents care about risk; however, she does not explicitly consider how exposure to risk may affect their decisions.

${ }^{6}$ Batra and Ullah (1974) consider input demand of a competitive firm under price uncertainty, but limit attention to the case of uncertain product price. Nickell (1977), in a study of the government's role in the creation of uncertainty by manipulating the environment in which private firms operate, assumes uncertainty is transmitted through demand for firms' products. Hartman (1972) examines the effect of uncertainty on output price, wage rate and investment costs on investment of a competitive firm with adjustment costs, but assumes the firm does not care about risk; see also Abel (1983) and Norstrøm (1974).

${ }^{7}$ See Baldursson and von der Fehr (2004a) for a further discussion of the assumptions underlying our analysis.

${ }^{8}$ For a textbook treatment, see for instance Ogden et al. (2002, pp. 86-88); for a critical appraisal of the (uncritical) application of the assumption of risk aversion, see Goldberg (1990). 
producing a pollutant. We assume a system of tradable quotas is in place, where firms may have been allocated some quotas at the outset and additional quotas may be purchased in the quota market at the prevailing quota price. $^{9}$ Before the (stochastic) price of quotas is revealed, firms decide on their production capacity; after observing the quota price, firms decide on output.

We first show that the product price is positively related to the quota price. Volatility of quota prices is therefore translated into volatility of the product price. Hence, firms are subject to both a revenue and a cost effect of a change in quota price. For firms that are 'dirty at the margin', i.e. a marginal increase in production leads to a large increase in emissions, the cost effect of a change in quota price dominates the revenue effect of a change in product price and so such firms respond to a rise in quota price by reducing output; conversely, a firm that is 'clean at the margin' will increase its output as the quota price rises. In the aggregate, however, the cost effect dominates and output falls with an increase in quota price.

For capacity decisions, the interplay of the output effect described above and the relationship between profits and prices is decisive. Intuitively, an addition to capacity will increase the variance in profits when profits and the change in profits resulting from the investment are positively correlated. For example, at a dirty firm which has been allocated no quota both profits and marginal profits fall when quota prices rise; hence, the firm reduces its exposure to risk by underinvesting relative to a risk-neutral benchmark. At a clean firm, due to the positive relation between product and quota prices, profits increase both on average and at the margin when prices go up; hence, also such a firm underinvests in order to reduce risk.

For dirty firms which are buyers on the quota market a larger initial allocation of quotas reduces their exposure to risk by reducing their net reliance on the quota market. For clean firms which are sellers on the quota market, however, a larger allocation of quotas increases their exposure to risk. It follows that in order to minimise exposure to risk and induce efficient investment behavior the initial allocation of quotas should follow a grandfathering type of rule, reflecting firms' emission characteristics.

When firms have access to forward trading in quotas, they choose contract positions so that they face the same subjective valuation of risk; forward trade therefore neutralises the impact of emissions characteristics and quota allocation on the relation between prices and profits. Whether a firm un-

\footnotetext{
${ }^{9}$ For the formal analysis, it does not matter exactly how quotas have been allocated initially. For some of the policy discussion, it is however implicit that the quota allocation is discretionary (although not necessarily gratis), conditional on firms' technology.
} 
derinvests or overinvests in production capacity is then solely determined by how its output is related to quota price. In the absence of wealth effects, initial quota allocation has no real effects.

The possibility of reducing emissions by cleaning, as in Baldursson and von der Fehr (2004a), does not change the fundamental nature of the above results, with the caveat that concepts 'clean' and 'dirty' must take cleaning into account. Investment in cleaning facilities is determined by how profits vary with the quota price. This is a similar result as obtained in Baldursson and von der Fehr (2004a), with the difference that here there is an additional effect caused by the induced change in output price. The implication is that firms underinvest in cleaning facilities with full quota. However, dirty firms with no quotas overinvest in cleaning facilities.

We also compare outcomes under a quota regime to those under a tax regime. It turns out that the comparison depends on the origin of uncertainty. If uncertainty regarding the quota price is driven by market conditions, then a regime with a fixed tax will remove risk concerning costs of emissions. If the underlying uncertainty is due to unpredictable policy changes caused by new information or changes in political attitudes or regimes, then the tax rate will be uncertain also and so outcomes may be similar.

The remainder of the paper is organised as follows. In the next two sections, we first introduce the basic model and then analyse the equilibrium of this model. In the three subsequent sections, we extend the basic model in various directions, by allowing for forward trading, by introducing the possibility of abatement and by endogenising the quota price. In the penultimate section, we analyse the case in which emissions are regulated by a tax rather than by quota and compare the two regulatory regimes. The final section contains our conclusions.

\section{Modelling framework}

We consider an industry with a continuum of firms which are infinitesimally small and price takers in all markets. Firms are indexed by $m$ and while the size of an individual firm is the differential $d m$ the aggregate 'mass' of firms in the industry is $M=1$. We usually omit the parameter $m$ when there is no risk of confusion.

Firm $m$ produces $x_{m}$ units of a final homogenous good and aggregate production is given by

$$
X=\int_{0}^{1} x_{m} d m .
$$

Costs at firm $m$ are given by a smooth function $c\left(x_{m}, y_{m} ; m\right)$, where $y_{m}$ 
is a choice variable of the firm. We will interpret this variable as production capacity, but other interpretations are possible, e.g. type of technology or research and development. We assume that $c$ is convex, increasing in $x$ and that an increase in capacity reduces marginal cost of output, $c_{x y}<0$.

The final-goods price $p$ is given by the inverse demand function

$$
p=p(X) \text {. }
$$

Inverse demand is smooth and strictly decreasing in aggregate output $X$, $p^{\prime}<0$.

Firm $m$ emits $\rho\left(x_{m} ; m\right)$ units of the pollutant. Emissions are non-decreasing in output, $\rho^{\prime} \geq 0$ for all $m$, and strictly increasing for a positive mass of firms. Aggregate production of the pollutant from firms in the industry is given by

$$
R=\int_{0}^{1} \rho\left(x_{m} ; m\right) d m
$$

We assume a tradable quota regime for controlling pollution is in place. Firm $m$ is allocated a quota $q_{m}$ which it uses to cover its emissions. Excess emissions $\rho-q$ must be purchased in the quota market at the prevailing quota price $r$; if the firm emits less than its allocated quota it sells its excess quota in the market. Since, in this paper, we are mainly concerned with how the quota price affects the final-goods price, we initially assume that $r$ is exogenously given and ex ante stochastic. A possible interpretation is that the quota market encompasses more industries than the one we study, and that this industry is sufficiently small that it does not affect equilibrium in the quota market. We treat the case of endogenous quota price in a later section.

The profit of firm $m$ is given by

$$
\pi_{m}=p x_{m}-c\left(x_{m}, y_{m} ; m\right)-r\left[\rho\left(x_{m} ; m\right)-q_{m}\right] .
$$

Firm $m$ maximises expected utility of profits $E U_{m}\left(\pi_{m}\right)$, where $U_{m}$ is an increasing, smooth and concave utility function.

Events occur as follows:

1. The government allocates emission quotas.

2. Firms choose levels of capacity $y_{m}, 0 \leq m \leq 1$.

3. The quota price $r \geq 0$ is realised.

4. Firms choose amounts of output $x_{m}, 0 \leq m \leq 1$. 
This setup captures the real market feature that firms make commitments before all uncertainty is resolved; specifically, firms must make capacity decisions before all prices are determined. In reality firms make a series of commitments, from building capacity to adjusting output to actual market conditions. Our model may be viewed as an abstraction where we divide time in two - before and after commitment is made.

Our setup thus represents an extension of the literature on decisions of risk-averse firms referred to above, where all decisions are made before uncertainty is resolved. In our model, firms are allowed some adjustment to prevailing market conditions. This feature facilitates an endogenous finalgoods price, where the market is equilibrated by firms setting output in response to realised prices.

Example: In what follows we sometimes use a parametrisation where emissions are proportional to output, the cost function is quadratic and the inverse-demand function is linear:

$$
\begin{aligned}
\rho(x) & =\alpha x, \quad \alpha>0 \\
c(x, y) & =\frac{\beta}{2}[x-y]^{2}+\gamma y, \quad \beta, \gamma>0 \\
p(X) & =1-X,
\end{aligned}
$$

where units have been chosen (without loss of generality) so as to make the intercept and the slope coefficients in the inverse-demand function equal to 1. Cost consists of two elements: 'production cost' $\frac{\beta}{2}[x-y]^{2}$ and 'capacity cost' $\gamma y$. Note that, for given capacity $y$, production cost is U-shaped, with a minimum at $x=y$ ('full capacity'). When output exceeds capacity, i.e. $x>y$ (which will be the case at equilibrium), a marginal increase in capacity increases capacity cost by $\gamma$ but reduces production cost by $\beta[x-y]$.

\section{Market equilibrium}

In this section we study the (subgame perfect) equilibrium of the model set out in the previous section. We solve the model by backwards induction, starting at Stage 4 where firms choose output levels and final-goods market equilibrium is determined. We then consider Stage 2 decisions where capacity levels are chosen, taking account of the behaviour of market participants and the equilibrium at Stage 4. 


\subsection{Final-goods market equilibrium}

Since at Stage 4 the quota price $r$ is known, firms choose output levels to maximise profits. The first-order condition for each firm is given by

$$
c_{x}+r \rho^{\prime}=p .
$$

In other words, firms choose output levels such that total marginal costs, including the cost of emissions, are set equal to output price. We assume that the second-order condition for profit maximisation,

$$
\Delta_{x}=c_{x x}+r \rho^{\prime \prime}>0,
$$

is satisfied. Note that $c_{x x}>0$ and $r \geq 0$, so the condition always holds for convex $\rho$. It immediately follows that output at each firm is increasing in the final-goods price.

Equilibrium in the final-goods market is determined by the first-order condition (7) for each firm, the aggregate output relation (1) and the inverse demand relation (2).

Note that the output profile $\left\{x_{m} ; 0 \leq m \leq 1\right\}$, and hence aggregate output, is dependent on the quota price $r$; therefore, so is the output price. More specifically, the impact of a marginal change in quota price on output at any given firm is

$$
\frac{d x}{d r}=\frac{1}{\Delta_{x}}\left[\frac{d p}{d r}-\rho^{\prime}\right],
$$

where $\frac{d p}{d r}$ is the effect of the change in quota price on equilibrium output price.

We first establish the relationship between quota price and equilibrium final-goods aggregate output and price.

Lemma 1 At equilibrium the supply of the final good is decreasing, and its price increasing, in the price of quotas

$$
\begin{aligned}
& \frac{d X}{d r}<0 \\
& \frac{d p}{d r}>0 .
\end{aligned}
$$

Proof: Suppose $\frac{d X}{d r} \geq 0$, or equivalently, since $\frac{d p}{d r}=p^{\prime} \frac{d X}{d r}$ and $p^{\prime}<0$, that $\frac{d p}{d r} \leq 0$. Then, from (8), the right-hand side of $(9)$ is non-positive for all firms and strictly negative for the positive mass of firms for which $\rho^{\prime}>0$. It follows that, given an increase in quota price, aggregate output will fall, and, 
since inverse demand is strictly decreasing in output, the final-goods price will increase, i.e. $\frac{d p}{d r}>0$, a contradiction. $Q E D$

The endogeneity of the final-goods price affects the relation between the quota price and the volume of output. If the final-goods price were exogenous - i.e. not influenced by changes in the quota price - then, subsequent to a rise in quota price, total marginal cost would rise and production would fall at all polluting firms. When the final-goods price is endogenous, however, there is an additional effect: the final-goods price rises with the quota price providing an incentive to increase supply. The emissions effect and the product-market effect go in opposite directions and, for any individual firm, the overall result depends on their relative strengths. The lemma states that in the aggregate it is the former effect that dominates.

Specifically, since the denominator of the right-hand side of (9) is positive, the direction of the response of output at a given firm to a change in the quota price, viz. the sign of $\frac{d x}{d r}$, is determined by the difference of two positive numbers, $\frac{d p}{d r}-\rho^{\prime}$; in particular, if $\rho^{\prime} \leq \frac{d p}{d r}$ then $\frac{d x}{d r} \geq 0$ and vice versa.

We shall refer to a firm with a technology such that $\rho^{\prime}>\frac{d p}{d r}$ for all $r$ as being 'dirty at the margin'; such a firm is characterised by a rapid increase of emissions with output. Conversely, we shall refer to a firm where $\rho^{\prime}<\frac{d p}{d r}$ for all $r$ as being 'clean at the margin'; at such a firm emissions rise slowly with output. By (9) and (11) we have the following result.

Proposition 2 A firm which is dirty at the margin reduces its output subsequent to a rise in quota price. Conversely, a firm which is clean at the margin will increase its output as quota price rises.

For a dirty firm where output falls as a consequence of a rise in the price of quotas, this effect is attenuated by the increase in final-goods price. For a clean firm, the product-market effect (11) dominates the emissions effect and output increases subsequent to a rise in quota price. Indeed, due to the product-market effect, a non-polluting firm will be affected by quota regulation and induced to increase output following an increase in quota price.

Example (continued): For the functional form specification in (4)-(6), we have

$$
\frac{d x}{d r}=\frac{1}{\beta}\left[\frac{d p}{d r}-\alpha\right]
$$


Furthermore,

$$
\begin{aligned}
\frac{d p}{d r} & =-\int_{m} \frac{d x}{d r} d m \\
& =-\left[B \frac{d p}{d r}-A\right],
\end{aligned}
$$

where $A=\int_{m} \frac{\alpha_{m}}{\beta_{m}} d m$ and $B=\int_{m} \frac{1}{\beta_{m}} d m$, implying that

$$
\frac{d p}{d r}=D \equiv \frac{A}{1+B}>0
$$

and so

$$
\frac{d x}{d r}=\xi \equiv \frac{D-\alpha}{\beta}
$$

In other words, we may write

$$
\begin{aligned}
& x=\xi r+\phi \\
& p=D r+G
\end{aligned}
$$

where $\xi$ and $\phi$ are firm-specific (i.e., dependent on $m$ ). Note that the finalgoods price is a linear transformation of quota price. Hence, the final product and quotas are perfect substitutes from a risk point of view.

In accordance with the general discussion above we have the intuitively reasonable result that for $\alpha<D$ (relatively clean firms) output is increasing in quota price, i.e. $\frac{d x}{d r}>0$, whereas for $\alpha \geq D$ (relatively dirty firms) the reverse holds. Note that here the characterisation of firm types is given by a comparison of exogenous parameters.

\subsection{Capacity decisions}

At Stage 2, the quota price is yet to be realised so firms maximise expected utility over capacity levels $y$ :

$$
\max _{y} E U(\pi)
$$

where

$$
\pi=p x-c(x, y)-r[\rho(x)-q] .
$$

The first-order condition for each firm is given by

$$
E\left[U^{\prime} c_{y}\right]=0,
$$


where we have used the relation $\frac{d \pi}{d y}=-c_{y}$. We assume that the second-order condition for expected-utility maximum,

$$
E\left[-U^{\prime \prime} c_{y}^{2}+U^{\prime} \frac{c_{x x} c_{y y}-c_{x y}^{2}+r c_{y y} \rho^{\prime \prime}}{c_{x x}+r \rho^{\prime \prime}}\right]>0
$$

is satisfied. Note that by convexity of $c, c_{x x}>0, c_{y y}>0$ and $c_{x x} c_{y y}-c_{x y}^{2}>0$. Since $r \geq 0$, the condition always holds for convex $\rho$.

A risk-neutral firm will choose $y=y^{n}$ such that $E c_{y}=0$. In effect, the risk-neutral firm chooses a capacity so as to minimise expected total cost. In the example, at $y=y^{n}, E c_{y}=E[\beta[x-y]]-\gamma=0$; that is, the cost of a marginal capacity addition is balanced by a reduction in expected production costs.

From the convexity of the cost function, it follows that if $E c_{y}<0$ capacity is smaller than the risk-neutral benchmark, i.e. $y<y^{n}$, and vice versa. The first-order condition (14) may be rewritten

$$
E c_{y}=-\frac{\operatorname{Cov}\left(U^{\prime}, c_{y}\right)}{E U^{\prime}}
$$

Since $U^{\prime}>0, E c_{y}>0$ if and only if $\operatorname{Cov}\left(U^{\prime}, c_{y}\right)<0$. We therefore have the following lemma:

Lemma 3 A risk-averse firm chooses a smaller capacity than a risk-neutral one if $\operatorname{Cov}\left(U^{\prime}, c_{y}\right)>0$ and vice versa.

To provide some intuition for this result, consider how capacity affects variation in profits:

$$
\frac{d \operatorname{Var}(\pi)}{d y}=\operatorname{Cov}\left(\pi, \frac{d \pi}{d y}\right)=-2 \operatorname{Cov}\left(\pi, c_{y}\right) .
$$

Put in differential terms, a marginal increase in capacity from $y_{0}$ to $y_{0}+d y$ will change profits from $\pi_{0}$ to $\pi_{0}+d \pi=\pi_{0}-c_{y} d y$; the additional differential term will reduce overall variance in profits when $\pi_{0}$ and $d \pi$ are negatively correlated, i.e. when $\pi_{0}$ and $c_{y}$ are positively correlated. Given that the sign of $\operatorname{Cov}\left(U^{\prime}, c_{y}\right)$ is opposite to that of $\operatorname{Cov}\left(\pi, c_{y}\right)$ (which is certainly the case with quadratic utility), $E c_{y}<0$ if and only if $\frac{d \operatorname{Var}(\pi)}{d y}>0$; that is, firms invest below the risk-neutral benchmark if and only if the investment increases variation in profits.

We have the following lemma: 
Lemma 4 A risk-averse firm invests less than the risk-neutral benchmark if for all $r$ the signs of $\frac{d \pi}{d r}$, given by

$$
\frac{d \pi}{d r}=x \frac{d p}{d r}-[\rho-q],
$$

and $\frac{d x}{d r}$, given by (9), are positive. The same is true if $\frac{d \pi}{d r}$ and $\frac{d x}{d r}$ are both everywhere negative. Conversely, if, for all $r$, the sign of $\frac{d \pi}{d r}$ is positive and that of $\frac{d x}{d r}$ is negative (or vice versa), the firm invests in excess of the riskneutral benchmark.

Proof: The stochastic variation in both $U^{\prime}$ and $c_{y}$ is driven by the quota price $r$. Specifically,

$$
\begin{aligned}
\frac{d U^{\prime}}{d r} & =U^{\prime \prime} \frac{d \pi}{d r} \\
\frac{d c_{y}}{d r} & =c_{x y} \frac{d x}{d r} .
\end{aligned}
$$

Since $U^{\prime \prime}<0, U^{\prime}$ will be increasing if $\frac{d \pi}{d r}<0$ for all $r$ and decreasing if $\frac{d \pi}{d r}>0$ for all $r$. Similarly, since $c_{x y}<0, c_{y}$ is increasing if $\frac{d x}{d r}<0$ for all $r$ and decreasing if $\frac{d x}{d r}>0$ for all $r$. It follows that if $\frac{d \pi}{d r}$ and $\frac{d x}{d r}$ have the same sign for a given $r$ so do $\frac{d U^{\prime}}{d r}$ and $\frac{d c_{y}}{d r}$, and vice versa. Therefore, if the signs of $\frac{d \pi}{d r}$ and $\frac{d x}{d r}$ are always positive (or always negative) $\operatorname{Cov}\left(U^{\prime}, c_{y}\right)$ is positive. Analogously, if $\frac{d \pi}{d r}$ is always positive and $\frac{d x}{d r}$ always negative (or vice versa), $\operatorname{Cov}\left(U^{\prime}, c_{y}\right)$ is negative. $Q E D$

We now consider the factors determining the signs of $\frac{d \pi}{d r}$ and $\frac{d x}{d r}$ and hence the incentives to invest in production capacity. Above we saw that the sign of $\frac{d x}{d r}$ is determined by the difference of the product-market effect $\frac{d p}{d r}$ and the emissions effect $\rho^{\prime}$. In particular, firms that are dirty at the margin will reduce their output, whereas firms that are clean at the margin will increase their output, when the price of quotas rises.

Concerning the sign of $\frac{d \pi}{d r}$ we note that, at optimum, an increase in quota price affects a firm's profits through two channels: sales of the final good and trade of quotas. Final-goods revenues increase due to a rise in final good price $\left(\frac{d p}{d r} x>0\right)$. A buyer of quotas $(\rho-q>0)$ will lose from a higher quota price, while a seller $(\rho-q<0)$ will gain. The net effect depends on whether the revenue or the quota effect dominates. Similarly, the net effect on output of an increase in quota price depends on whether the increase in final-goods price exceeds or falls below the increase in costs of covering the marginal increase in emissions. 
Suppose no quotas have been allocated initially, i.e. $q \equiv 0$. This implies that

$$
\begin{aligned}
& \frac{d \pi}{d r}=x\left[\frac{d p}{d r}-\frac{\rho}{x}\right], \\
& \frac{d x}{d r}=\frac{1}{\Delta_{x}}\left[\frac{d p}{d r}-\rho^{\prime}\right] .
\end{aligned}
$$

The sign of $\frac{d \pi}{d r}$ is determined by the difference between the marginal effect of quota price on output price and average pollution; in particular, profits increase if the rise in final-goods price exceeds the rise in quota cost per unit of output. The sign of $\frac{d x}{d r}$ is determined by the difference between the marginal effect of quota price on output price and marginal pollution; in particular, output increases if the rise in final-goods price exceeds the marginal rise in quota cost.

Consider a firm which has dirty technology, both on average and at the margin (i.e. $\frac{\rho}{x}>\frac{d p}{d r}$ and $\rho^{\prime}>\frac{d p}{d r}$ for all possible values of $r$ ). Then both profits and production of the final good are negatively related to the permit price, i.e. $\frac{d \pi}{d r}<0$ and $\frac{d x}{d r}<0$. Such a firm will therefore invest in less capacity than if it were risk-neutral. Note that the product-market effect taken in isolation tends to reduce the impact of risk and makes behaviour more like that of a risk-neutral firm. The reason for this is that the absolute value of both $\frac{d \pi}{d r}$ and $\frac{d x}{d r}$ is less than if we had $\frac{d p}{d r}=0$, and hence the covariance is smaller.

Consider next a firm with relatively clean technology (i.e. $\frac{\rho}{x}<\frac{d p}{d r}$ and $\rho^{\prime}<\frac{d p}{d r}$ for all possible values of $r$ ). Then both profits and production of the final good are positively related to the permit price, i.e. $\frac{d \pi}{d r}>0$ and $\frac{d x}{d r}>0$. Such a firm will also invest in less capacity than if it were riskneutral. For a perfectly clean firm (i.e. $\frac{\rho}{x} \equiv \rho^{\prime} \equiv 0$ ) this is entirely due to the product-market effect; if the final-goods price was not affected by the quota price the firm would not be subjected to any risk and would therefore choose the risk-neutral benchmark. Thus, while for dirty firms the product-market effect ameliorates the exposure to risk arising from variations in quota price, clean firms face risk only due to the interaction of product and quota market prices.

Between these two extremes we can imagine intermediate cases. For example, there may be technologies that are clean on average, but dirty at the margin (i.e. $\frac{\rho}{x}<\frac{d p}{d r}<\rho^{\prime}$ ). Conversely, there may exist technologies that are clean at the margin, but dirty on average (i.e. $\rho^{\prime}<\frac{d p}{d r}<\frac{\rho}{x}$ ). In both cases $\frac{d \pi}{d r}$ and $\frac{d x}{d r}$ have opposite signs, so $\operatorname{Cov}\left(U^{\prime}, c_{y}\right)<0$ resulting in investment over the cost-minimising (risk-neutral) level. Note, however, that as for any dirty technology, in absence of the product-market effect these intermediate firms 
would invest less than the risk-neutral benchmark.

We highlight the main conclusions of the above discussion in the following proposition:

Proposition 5 For a risk-averse firm that has been allocated no quotas (i.e. $q=0$ ), the following table characterises investment relative to the risk-neutral benchmark:

\begin{tabular}{|c|c|c|}
\hline & $\begin{array}{c}\text { Clean at margin } \\
\left(\rho^{\prime}<\frac{d p}{d r} \text {, all } r\right)\end{array}$ & $\begin{array}{c}\text { Dirty at margin } \\
\left(\rho^{\prime}>\frac{d p}{d r} \text {, all } r\right)\end{array}$ \\
\hline $\begin{array}{c}\text { Clean on average } \\
\left(\frac{\rho}{x}<\frac{d p}{d r} \text {, all } r\right)\end{array}$ & $y<y^{n}$ & $y>y^{n}$ \\
\hline $\begin{array}{c}\text { Dirty on average } \\
\left(\frac{\rho}{x}>\frac{d p}{d r} \text {, all } r\right)\end{array}$ & $y>y^{n}$ & $y<y^{n}$ \\
\hline
\end{tabular}

For perfectly clean firms (i.e. $\rho \equiv 0$ ), underinvestment is entirely due to the impact of quota prices on final-goods prices; for dirty firms, this productmarket effect tends to ameliorate underinvestment.

Example (continued): By (4) average and marginal emissions are constant at each firm, i.e. $\frac{\rho}{x}=\rho^{\prime}=\alpha$. Therefore, by (17) and (9), the signs of $\frac{d \pi}{d r}$ and $\frac{d x}{d r}$ are determined by the sign of $\frac{d p}{d r}-\alpha=D-\alpha$ when $q=0$. By Lemma 4 , all firms invest below the risk-neutral benchmark in this case.

Returning to the general case, we move on to discuss the impact of initial quota allocation. By (9), allocation of quotas does not influence the relation between final-goods supply of an individual firm and price of quotas, i.e. $\frac{d x}{d r}$. However, by (17) allocation of quotas affects the relation between profits and quota price; specifically, $\frac{d \pi}{d r}$ is driven up by a rise in $q$.

It follows that for a firm which is clean on average quota allocation increases risk exposure. This is due to a portfolio effect; quota allocation corresponds to the addition of a risky asset positively correlated to the original portfolio (capacity). The firm responds by balancing its portfolio in the only way it can, viz. by changing its capacity. A firm that is clean both on average and at the margin always underinvests, while a firm that is clean on average but dirty at the margin, always overinvests.

For a firm that is dirty on average quota allocation up to a certain level reduces risk exposure. A large enough quota allocation, however, leads to a positive relation between profits and quota price. A firm that is dirty both on average and at the margin therefore invests above the risk-neutral benchmark with a sufficiently large quota; conversely, a firm that is dirty on average 
but clean at the margin underinvests with a large quota. By continuity, there exists an intermediate quota allocation such that investment minimises expected costs. This level of quota is lower than total emissions, since, by (17), $\frac{d \pi}{d r}>0$ if $q \geq \rho$.

The following proposition summarises the policy implications of the above effects of quota allocation.

Proposition 6 In order to minimise exposure to risk, firms that are clean on average (i.e. $\frac{\rho}{x}<\frac{d p}{d r}$ for all possible values of $r$ ) should not be allocated any quotas; firms that are dirty on average (i.e. $\frac{\rho}{x}>\frac{d p}{d r}$ for all possible values of $r$ ) should be allocated some quotas, but not sufficient to cover all of their emissions.

The proposition may be interpreted as a grandfathering rule, viz. that allocation should be related to emissions. Specifically, if the goal is to minimise risk exposure, or induce efficient investment behaviour, low-emission firms should not be allocated any quotas while high-emission firms should be allocated at least some quotas, although not fully corresponding to their emissions in the absence of regulation. For the latter group there exists a quota allocation that leads firms to invest optimally in the sense that $E\left[c_{y}\right]=0$ or $\operatorname{Cov}\left(U^{\prime}, c_{y}\right)=0$.

Intuitively, from the above discussion we would expect a monotone relationship between capacity and quota allocation. From the first-order condition (14), we find

$$
\frac{d y}{d q}=-\frac{\frac{\partial E\left[U^{\prime} c_{y}\right]}{\partial q}}{\frac{\partial E\left[U^{\prime} c_{y}\right]}{\partial y}}=\frac{E\left[r U^{\prime \prime} c_{y}\right]}{\frac{\partial E\left[-U^{\prime} c_{y}\right]}{\partial y}}
$$

where we have used the Envelope Theorem and the fact that, from (7), $\frac{d x}{d q}=0$ for given $y$. From the second-order condition for $y$, it follows that the denominator is negative. As for the numerator, we have $r U^{\prime \prime}<0$. However, since $c_{y}$ can be both positive and negative, the sign of the numerator depends on the higher-order characteristics of the utility and cost functions and the distribution of $r$. We can therefore not conclude in general that the relationship between capacity and quota allocation is monotone.

In the case of a quadratic utility function, where $U^{\prime \prime}$ is constant, we have

$$
\begin{aligned}
E\left[r U^{\prime \prime} c_{y}\right] & =U^{\prime \prime} E\left[r c_{y}\right] \\
& =U^{\prime \prime}\left[\operatorname{Cov}\left(r, c_{y}\right)+E r E c_{y}\right] .
\end{aligned}
$$

Since $U^{\prime \prime}<0$, the sign of $\frac{d y}{d q}$ is the same as that of $\operatorname{Cov}\left(r, c_{y}\right)+\operatorname{ErE} c_{y}$. Because $c_{x y}<0, \operatorname{Cov}\left(r, c_{y}\right)$ is negative if $\frac{d x}{d r}>0$ which is the case for firms 
that are clean at the margin; conversely, $\operatorname{Cov}\left(r, c_{y}\right)$ is positive for firms that are dirty at the margin. Moreover, while $E r$ is always positive $E c_{y}$ is negative for firms that underinvest and positive for those that overinvest. It follows that if, for example, a firm is clean both at the margin and on average, it underinvests, and so both $\operatorname{Cov}\left(r, c_{y}\right)<0$ and $E c_{y}<0$; hence $\frac{d y}{d q}<0$ so investment is further reduced by a larger quota allocation.

Summing up, we have:

Proposition 7 The following table characterises how investment of a riskaverse firm relates to its initial quota allocation, $q$ :

\begin{tabular}{|c|c|c|}
\hline & $\begin{array}{l}\text { Clean at margin } \\
\left(\rho^{\prime}<\frac{d p}{d r} \text {, all } r\right)\end{array}$ & $\begin{array}{l}\text { Dirty at margin } \\
\left(\rho^{\prime}>\frac{d p}{d r}, \text { all } r\right)\end{array}$ \\
\hline $\begin{array}{l}\text { Clean on average } \\
\qquad\left(\frac{\rho}{x}<\frac{d p}{d r} \text {, all } r\right)\end{array}$ & $\begin{array}{c}y<y^{n}, \text { all } q \\
\text { risk increasing in } q \\
\frac{d y}{d q}<0 \text { if } U^{\prime \prime} \text { const }\end{array}$ & $\begin{array}{c}y>y^{n}, \text { all } q \\
\text { risk increasing in } q \\
\frac{d y}{d q}>0 \text { if } U^{\prime \prime} \text { const }\end{array}$ \\
\hline $\begin{array}{c}\text { Dirty on average } \\
\left(\frac{\rho}{x}>\frac{d p}{d r}, \text { all } r\right)\end{array}$ & $\begin{array}{l}y \gtrless y^{n} \text { for } q \lessgtr \widetilde{q}, \text { some } \widetilde{q} \\
\frac{d y}{d q}<0 \text { if } U^{\prime \prime} \text { const, q large }\end{array}$ & $\begin{array}{l}y \lessgtr y^{n} \text { for } q \lessgtr \widehat{q}, \text { some } \widehat{q} \\
\frac{d y}{d q}>0 \text { if } U^{\prime \prime} \text { const, } q \text { large }\end{array}$ \\
\hline
\end{tabular}

Example (continued): With the parametrisation (4)-(6), all firms are either clean or dirty depending on whether $\alpha<D$ or $\alpha>D$. The diagonal elements in the table of the proposition therefore fully characterise all possible outcomes.

\section{Forward markets}

So far, it has been assumed that all trade, both in final-goods and quota markets, takes place after investment has occured; consequently, the only way a firm can handle risk is by adjusting its capacity. We now consider the possibility that firms can hedge by trading forward. Specifically, we assume that there exist futures markets for both final goods and quotas. Firm m's sale of the final-goods on the futures market is denoted $\bar{x}_{m}$, while the quantity it buys forward on the quota market is denoted $\bar{q}_{m}$. Futures prices are $\bar{p}$ and $\bar{r}$ for final goods and quotas, respectively. As with the spot price of quotas, we take the futures price of quotas as exogenously given. The futures price of the final-good, however, is determined endogenously in the model. Firms make decisions about investment and trade on the futures markets simultaneously (i.e. at Stage 2 in the move order).

At Stage 4, a firm maximises its profits, which now are given by 


$$
\pi=p[x-\bar{x}]+\overline{p x}-c(x, y)-r[\rho-q-\bar{q}]-\overline{r q},
$$

by choosing final-goods output $x$. As before, we find that the first-order condition for this problem is given by (7) while the relationship between quota price and final-goods output is given by (9).

At Stage 2, a firm chooses capacity $y$, as well as forward trade of the final good $\bar{x}$ and the quota $\bar{q}$. Before analysing optimal behaviour, we briefly consider the marginal effects on the firm's expected utility of forward contracting:

$$
\begin{aligned}
& \frac{d E U}{d \bar{q}}=\operatorname{Cov}\left(U^{\prime}, r\right)+E U^{\prime}[E r-\bar{r}] \\
& \frac{d E U}{d \bar{x}}=\operatorname{Cov}\left(U^{\prime}, p\right)+E U^{\prime}[E p-\bar{p}]
\end{aligned}
$$

The first element on the right hand side of these two expressions represents the marginal effect of forward contracting on risk exposure; it is given by the covariance between marginal utility and spot price. The second element represents the marginal effect of arbitrage, or buying forward and reselling spot; it is given by the expected difference between spot and forward prices, weighted by expected marginal utility. At optimum, these two effects will be balanced.

The first-order conditions for the Stage 2 expected-utility maximisation problem become

$$
\begin{aligned}
E c_{y} & =-\frac{\operatorname{Cov}\left(U^{\prime}, c_{y}\right)}{E U^{\prime}} \\
E r-\bar{r} & =\frac{\operatorname{Cov}\left(U^{\prime}, r\right)}{E U^{\prime}} \\
E p-\bar{p} & =\frac{\operatorname{Cov}\left(U^{\prime}, p\right)}{E U^{\prime}}
\end{aligned}
$$

The first of these conditions corresponds to (16) above. The two last conditions equate the difference in expected spot and forward prices for quotas and final good, respectively, to what may be thought of as the market value of risk associated with these products.

Since, for quotas, both the forward price and (the distribution of) the spot price are exogenously given, the market value of risk of quotas is in effect predetermined. It may be both positive or negative, depending upon the assumption about the expected difference between spot and forward prices. ${ }^{10}$

\footnotetext{
${ }^{10}$ We may think of the difference $E r-\bar{r}$ as being determined in accordance with the CAPM, i.e. that its sign and size is dependent on the non-diversifiable risk of $r$ and the market price of risk.
} 
Moreover, firms behave such that, at optimum, they all have the same subjective valuation of quota-price risk. This implies that $\frac{\operatorname{Cov}\left(U^{\prime}, r\right)}{E U^{\prime}}$ is identical across all firms; in other words, independently of their emission technology and allocation of quotas; trade on the forward markets leads all firms to positions so that the sign of the covariance between quota price and marginal utility of profits is the same.

We get a similar result concerning the valuation of final-goods price risk; again, forward trade leads to positions so that the subjective valution of risk is the same and hence so is the sign of the covariance between final-goods price and marginal utility of profits.

Intuitively we would expect that $\operatorname{Cov}\left(U^{\prime}, p\right)$ and $\operatorname{Cov}\left(U^{\prime}, r\right)$ have the same sign, since $\frac{d p}{d r}>0$. Moreover, we would expect that $\operatorname{Cov}\left(U^{\prime}, c_{y}\right)$ has the opposite sign to $\operatorname{Cov}\left(U^{\prime}, r\right)$ for clean firms, because for such firms $\frac{d}{d r} c_{y}=$ $c_{x y} \frac{d x}{d r}<0$; conversely, we would expect the same sign for $\operatorname{Cov}\left(U^{\prime}, c_{y}\right)$ and $\operatorname{Cov}\left(U^{\prime}, r\right)$ for dirty firms, since for them $\frac{d}{d r} c_{y}>0$. We have not been able to prove this in general, but the result goes through for reasonable parametrisations of cost and abatement technologies.

Example (continued): In this case, $p=D r+G$ and so

$$
\operatorname{Cov}\left(U^{\prime}, p\right)=\operatorname{DCov}\left(U^{\prime}, r\right),
$$

implying that $E p-\bar{p}=D[E r-\bar{r}]$, so $\bar{r} \gtrless E r \Longleftrightarrow \bar{p} \gtrless E p$. Here, forward contracts in final good and quota are perfect substitutes.

We further find

$$
\begin{aligned}
\operatorname{Cov}\left(U^{\prime}, c_{y}\right) & =\operatorname{Cov}\left(U^{\prime},-\beta[x-y]+\gamma\right) \\
& =-\beta \operatorname{Cov}\left(U^{\prime}, x\right) \\
& =-\beta E \operatorname{Cov}\left(U^{\prime}, r\right) \\
& =[\alpha-D] \operatorname{Cov}\left(U^{\prime}, r\right),
\end{aligned}
$$

implying that $\operatorname{sign}\left(\operatorname{Cov}\left(U^{\prime}, c_{y}\right)\right)=\operatorname{sign}\left(\operatorname{Cov}\left(U^{\prime}, r\right)\right)$ iff $\alpha>D$. Therefore, if the risk premium in the quota market is positive, so $E r-\bar{r}>0$ and $\operatorname{Cov}\left(U^{\prime}, r\right)>0$, firms with dirty technologies invest above, and firms with clean technologies invest below, the risk-neutral benchmark; if the risk premium in the quota market is negative, we have the opposite result.

Note that the result that dirty firms overinvest when clean firms underinvest and vice versa, holds independently of quota allocations; in particular, the result holds when firms have not been allocated any quotas. This is different from the case analysed in the previous section, where firms did not have the opportunity to trade in forward markets; then, both clean and dirty firms underinvest if they have not been allocated any quotas. With the opportunity to trade on forward markets, firms choose contract positions so 
that they face the same subjective valuation of price risk, implying that the sign of the covariance between profits and price is the same, irrespective of technology. In other words, trade on forward markets in effect neutralises the impact of technology on the relation between price and profits. In this case, therefore, whether a firm underinvests or overinvests is determined by how output is related to the quota price, which does depend on technology but not on quota allocation.

In the example, if prices on the forward and spot quota markets were 'unbiased' (Viane and Zilcha, 1998), i.e. $E r=\bar{r}$, prices on the forward and spot market for the final good would be unbiased also. Moreover, we would have $\operatorname{Cov}\left(U^{\prime}, c_{y}\right)=0$, and so $E c_{y}=0$; that is, capacity investment would be equal to the risk-neutral benchmark. Clearly, these results depend critically on the specific parametrisation; with more general functional forms, firms' capacity decisions would be influenced by risk even if market prices were unbiased. This is different from previous literature (e.g. Viane and Zilcha, 1998), where shocks are transmitted through prices and decisions are taken ex ante; then unbiased prices allow for perfect and costless hedging. In our set up, where firms may adjust output to prevailing market conditions, firms will always be exposed to risk at the margin, whatever their positions in the contract markets.

In the general case, in order to study the impact of quota allocation we differentiate the first-order conditions for $y, \bar{q}$ and $\bar{x}$ (20)-(22) and get

$$
\Phi\left[\begin{array}{l}
d \bar{q} \\
d \bar{x} \\
d y
\end{array}\right]=-\Psi d q
$$

where

$$
\begin{gathered}
\Phi=\left[\begin{array}{ccc}
E\left[U^{\prime \prime}[r-\bar{r}]^{2}\right] & E\left[U^{\prime \prime}[r-\bar{r}][p-\bar{p}]\right] & E\left[U^{\prime \prime} c_{y}[r-\bar{r}]\right] \\
E\left[U^{\prime \prime}[r-\bar{r}][p-\bar{p}]\right] & E\left[U^{\prime \prime}[p-\bar{p}]^{2}\right] & E\left[U^{\prime \prime} c_{y}[p-\bar{p}]\right] \\
E\left[U^{\prime \prime} c_{y}[r-\bar{r}]\right] & E\left[U^{\prime \prime} c_{y}[p-\bar{p}]\right] & E\left[U^{\prime \prime} c_{y}^{2}\right]
\end{array}\right] \\
\Psi=\left[\begin{array}{c}
E\left[U^{\prime \prime} r[r-\bar{r}]\right] \\
E\left[U^{\prime \prime} r[p-\bar{p}]\right] \\
E\left[U^{\prime \prime} r c_{y}\right]
\end{array}\right]
\end{gathered}
$$

It turns out that this system of equations has an explicit solution in the case of constant absolute risk aversion (CARA preferences), $U^{\prime \prime}=-\delta U^{\prime}$, where $\delta$ is a constant. Using first-order conditions, the matrix $\Psi$ can then 
be written

$$
\Psi=\left[\begin{array}{c}
E\left[U^{\prime \prime}[r-\bar{r}]^{2}\right] \\
E\left[U^{\prime \prime}[r-\bar{r}][p-\bar{p}]\right] \\
E\left[U^{\prime \prime} c_{y}[r-\bar{r}]\right]
\end{array}\right] .
$$

We therefore have a linear system of the form

$$
\left[\begin{array}{lll}
a_{11} & a_{12} & a_{13} \\
a_{21} & a_{22} & a_{23} \\
a_{31} & a_{32} & a_{33}
\end{array}\right]\left[\begin{array}{l}
d \bar{q} \\
d \bar{x} \\
d y
\end{array}\right]=-\left[\begin{array}{l}
a_{11} \\
a_{21} \\
a_{31}
\end{array}\right] d q
$$

which has the solution

$$
\begin{aligned}
& \frac{d \bar{q}}{d q}=-1 \\
& \frac{d \bar{x}}{d q}=0 \\
& \frac{d y}{d q}=0
\end{aligned}
$$

The conclusion is that, in this case, quota allocation has no real effects. Firms offset changes in quota allocation by trading in the forward quota market, but neither trade in forward final-goods market nor investment is affected.

To sum up, we have demonstrated that access to forward markets does not eliminate the impact of risk on capacity investement. However, the ability to hedge risk in quota and product markets changes the relationship between firm type and behaviour. Finally, allocation of quotas does not necessarily have any effect on behaviour; if it does, it is through wealth effects.

\section{Abatement}

So far we have have assumed that firms can only reduce emissions by reducing output of the final good. In this section we assume, along the lines of Baldursson and von der Fehr (2004a), that firms have access to two different technologies to reduce emissions for any given level of output, which we shall refer to as investment and abatement. These should be regarded as idealisations; the former of capital intensive, sunk-cost cleaning technologies with low variable costs, but long lead-times of investment; the latter of technologies which can be implemented comparatively quickly with low investment costs, but high variable costs. An example of the former technology 
is investment in scrubbers to reduce $\mathrm{SO}_{2}$ emissions in electricity generation from coal; an example of the latter is the use of 'cleaner' raw materials, e.g. low-sulphur coal for electricity generation. We investigate how allowing for cleaning affects results above. In addition, we extend the analysis of Baldursson and von der Fehr (2004a) - where firms' production of the pollutant and behaviour on the final-goods market were both taken as exogenous - by studying the effects of allowing for endogenous output price and pollution production on incentives to clean.

Denote investment by firm $m, m \in[0,1]$, by $k_{m}$ and abatement by $a_{m}$. Then aggregate investment and abatement, respectively, equal

$$
\begin{aligned}
K & =\int_{0}^{1} k_{m} d m, \\
A & =\int_{0}^{1} a_{m} d m .
\end{aligned}
$$

Firm $m$ 's emissions become $\rho\left(x_{m} ; m\right)-a_{m}-k_{m}$ while firm $m$ 's net trade in the quota market is $\rho\left(x_{m} ; m\right)-a_{m}-k_{m}-q_{m}$.

Costs at firm $m$ are now given by a smooth function $c\left(x_{m}, a_{m}, y_{m}, k_{m} ; m\right)$. We assume that that $c$ is increasing and convex. Furthermore, we retain the assumption that $c_{x y}<0$. We also assume that pollution cannot be completely cleaned, i.e. $\rho-a-k>0$.

We assume that, in the order of events, investment $(k)$ is chosen together with capacity $(y)$ at Stage 2 , while abatement $(a)$ is chosen with output $(x)$ at Stage 4.

At Stage 4, a firm maximises its profits, which now are given by

$$
\pi=p x-c(x, a, y, k)-r[\rho(x)-a-k-q]
$$

by choosing final-goods output $x$ and abatement $a$. The first-order conditions for this problem are given by

$$
\begin{aligned}
c_{x}+r \rho^{\prime} & =p \\
c_{a} & =r
\end{aligned}
$$

where (23) corresponds to (7). We assume that the second-order conditions

$$
\begin{aligned}
\Delta_{x} & =c_{x x}+r \rho^{\prime \prime}>0 \\
c_{a a} & >0 \\
\Delta_{a x} & =c_{a a} c_{x x}-\left[c_{a x}\right]^{2}+r \rho^{\prime \prime} c_{a a}>0
\end{aligned}
$$

are satisfied. Note that by convexity of $c, c_{x x}>0, c_{a a}>0$ and $c_{x x} c_{y y}-c_{x y}^{2}>$ 0 . Since $r \geq 0$, the condition always holds for convex $\rho$. 
Differentiating the first-order conditions and solving, we find the following relationship between the quota price and final-goods output and abatement, respectively:

$$
\begin{aligned}
& \frac{d x}{d r}=\frac{1}{\Delta_{a x}}\left\{\left[\frac{d p}{d r}-\rho^{\prime}\right] c_{a a}-c_{x a}\right\}, \\
& \frac{d a}{d r}=\frac{1}{\Delta_{a x}}\left\{c_{x x}+r \rho^{\prime \prime}-\left[\frac{d p}{d r}-\rho^{\prime}\right] c_{a x}\right\} .
\end{aligned}
$$

Note that the interaction between output and abatement choices is only via costs; specifically, if $c_{a x}=0,(25)$ reduces to (9) and (26) to $\frac{d a}{d r}=\frac{1}{c_{a a}}$. It follows that $\frac{d p}{d r}>0$ and that $\frac{d x}{d r}$ is positive or negative depending on whether the firm is clean or dirty on the margin. Furthermore, since $c_{a a}>0$ we have $\frac{d a}{d r}>0$, i.e. abatement goes up at all firms following an increase in quota price. Below we consider the more general case when $c_{a x}$ is non-zero.

We first check whether the final-goods price is increasing in quota price, i.e. whether $\frac{d p}{d r}>0$. Note that the proof of Lemma 1 was based on the argument that, if the final-goods price were decreasing in quota price, the market would not equilibrate because demand would go up but supply would go down following a rise in quota price, as some firms would reduce output and none would increase it. The argument goes through if marginal production costs do not fall too rapidly with abatement; in particular, $-c_{a x} \leq \rho^{\prime} c_{a a}$ is a sufficient condition to ensure $\frac{d p}{d r}>0$.

Given that final-goods price is increasing in quota price, we again find that how output of any given firm reacts to quota price depends on how dirty or clean its technology is at the margin. However, the possibility of abatement introduces an additional effect. If higher output means higher marginal abatement costs (or, which is the same, higher abatement means higher marginal production costs), i.e. $c_{x a}>0$, this effect tends to reduce output when quota price goes up; conversely, if higher output lowers marginal abatement costs, this effect tends to increase output.

The impact of quota price on individual firms' abatement also depends on how clean or dirty the firm is at the margin, as well as on the relationship between abatement and marginal production costs. If $c_{a x}$ is positive, a firm which is dirty at the margin (i.e. $\rho^{\prime}>\frac{d p}{d r}$ ) will increase abatement following a rise in quota price; conversely, if $c_{a x}<0$, a firm that is clean at the margin will do the same. Abatement can only fall following an increase in quota price if either the firm is dirty at the margin and $c_{a x}$ is negative and large in absolute value or if the firm is clean at the margin and $c_{a x}$ is positive and large.

We note that, compared to when firms' behaviour on the final-goods market is taken as exogenous (as in Baldursson and von der Fehr, 2004a), in 
which case abatement would surely go up following a rise in quota price, here the relationship between quota price and abatement is more complicated; whether or not final-goods market behaviour weakens or strenghtens the impact of quota price on abatement is however not clear but depends on the finer details of the model.

At Stage 2, a firm chooses capacity $y$ and investment $k$ so as to maximise expected utility. The first-order conditions for this problem become

$$
\begin{aligned}
& E c_{y}=-\frac{\operatorname{Cov}\left(U^{\prime}, c_{y}\right)}{E U^{\prime}} \\
& E c_{k}=E r+\frac{\operatorname{Cov}\left(U^{\prime}, r-c_{k}\right)}{E U^{\prime}}
\end{aligned}
$$

where (27) corresponds to (14). We again assume that the second-order conditions are satisfied.

A risk-neutral firm would choose $y$ and $k$ so that $E c_{y}=0$ and $E c_{k}=E r$, respectively; in particular, such a firm would invest in cleaning facilities up to the point where expected marginal costs equal expected quota price. A riskaverse firm would choose investment so that $E c_{k}<E r$ if $\operatorname{Cov}\left(U^{\prime}, r-c_{k}\right)<0$, and vice versa.

We find

$$
\begin{aligned}
\frac{d c_{y}}{d r} & =c_{y x} \frac{d x}{d r}+c_{y a} \frac{d a}{d r}=-\left[\frac{d p}{d r}-\rho^{\prime}\right] \frac{d x}{d y}-\frac{d a}{d y} \\
\frac{d\left[r-c_{k}\right]}{d r} & =1-c_{k x} \frac{d x}{d r}-c_{k a} \frac{d a}{d r}=1-\left[\frac{d p}{d r}-\rho^{\prime}\right] \frac{d x}{d k}-\frac{d a}{d k}
\end{aligned}
$$

where we have used the relationships

$$
\begin{aligned}
& \frac{d x}{d k}=\frac{1}{\Delta_{a x}}\left[c_{a k} c_{x a}-c_{x k} c_{a a}\right], \\
& \frac{d a}{d k}=\frac{1}{\Delta_{a x}}\left\{c_{a x} c_{x k}-c_{a k}\left[c_{x x}+r \rho^{\prime \prime}\right]\right\},
\end{aligned}
$$

and

$$
\begin{aligned}
& \frac{d x}{d y}=\frac{1}{\Delta_{a x}}\left[c_{a y} c_{x a}-c_{x y} c_{a a}\right], \\
& \frac{d a}{d y}=\frac{1}{\Delta_{a x}}\left\{c_{a x} c_{x y}-c_{a y}\left[c_{x x}+r \rho^{\prime \prime}\right]\right\} .
\end{aligned}
$$


Again, the characterisation of behaviour is determined by the shape of the cost function. We limit attention to the case in which costs of production and cleaning are separable, i.e. that the cost function $c$ is of the form

$$
c(x, a, y, k)=c^{1}(x, y)+c^{2}(a, k) .
$$

This implies that all cross-derivatives between production variables and cleaning variables are zero:

$$
c_{x a}=c_{x k}=c_{y a}=c_{y k}=0 .
$$

From (27), it is clear that, for given $k$, there is underinvestment in production capacity, as compared to the risk-neutral benchmark, if and only if $\operatorname{Cov}\left(U^{\prime}, c_{y}\right)>0$ and a risk-averse firm will underinvest if $\frac{d x}{d r}$ and $\frac{d \pi}{d r}$ are either both positive or both negative for all $r$. Note that by the envelope theorem we have

$$
\frac{d \pi}{d r}=x \frac{d p}{d r}-[\rho-a-k-q]
$$

which implies that the results in Section 3.2 above are still valid with the concepts 'clean on average' and 'dirty on average' defined by the conditions that $\frac{d p}{d r}>\frac{\rho-a-k}{x}$ and $\frac{d p}{d r}<\frac{\rho-a-k}{x}$, respectively. Instead of the simple characterisation of technology that was possible without abatement we must now take cleaning into account; whether a firm is clean or not depends on its cleaning decisions. Clearly, a firm that is clean in the absolute sense that $\frac{d p}{d r}>\frac{\rho}{x}$ will also be clean in this more general definition. However, the opposite is not true: a firm which is dirty on average in the absolute sense may be clean when cleaning is taken into consideration.

As regards investment in cleaning facilities, note that by (33) we have $\frac{d\left[r-c_{k}\right]}{d r}=1-\frac{c_{a k}}{c_{a a}}>0$ if $\left|c_{a k}\right|<c_{a a}$. It follows that, for given $y$, the firm underinvests in cleaning facilities if $\frac{d \pi}{d r}>0$ for all $r$ and vice versa. This is a similar result as obtained in Baldursson and von der Fehr (2004a) with the difference that there the output price is exogenous and hence the variation in profit depended on the net position in the quota market, $\rho-a-k-q$, only. Here there is an additional effect caused by the induced change in output price. The product market term is always positive so for a net seller in the quota market, where $\rho-a-k-q<0$, the positive relationship between profits and quota price is strengthened by the product market effect; conversely, for a net buyer of quotas, where $\rho-a-k-q>0$, the product market effect mitigates and may reverse a negative relationship between profits and quota price. It follows that with sufficiently generous quota allocation, so $q \geq \rho$, the firm underinvests in cleaning facilities (cf. Lemma 4 in Baldursson and von der Fehr, 2004a). A firm with no quotas allocated intially, so $q=0$, 
underinvests in cleaning facilities if it is clean on average and overinvests if it is dirty on average. The implication is the same as that stated in Proposition 6 , viz. that a grandfathering rule limits the exposure of firms to risk and hence incentives to deviate from the risk-neutral benchmark.

\section{Quota-Market Equilibrium}

The above analysis is based on the assumption that the quota price is exogenous. This is not an unreasonable assumption when the industry under consideration constitutes a limited part of the overall market. The quota price is then determined by conditions in the larger market; uncertainty is therefore a consequence of changes there. We now consider the case when the quota price is endogenous.

For simplicity we go to the other extreme and assume that the quota market is comprised solely of the industry under consideration so the same firms are active in the product and quota markets. We assume that the government sets an overall (and binding) target for emissions, $0<\bar{Q}<\infty$. In addition to quotas initially allocated, the government trades on the quota market in order to achieve the target. The quota price is then determined by the equilibrium condition

$$
\int_{0}^{1}\left[\rho_{m}-a_{m}-k_{m}\right] d m=\bar{Q}
$$

which states that aggregate emissions equal the emissions target. Alternatively, taking allocated quotas into consideration, we may state the equilibrium condition that firms' net demand for quotas equals the government's net supply, that is

$$
\int_{0}^{1}\left[\rho_{m}-a_{m}-k_{m}-q_{m}\right] d m=\bar{Q}-Q_{0}=\Delta Q,
$$

where $Q_{0}=\int_{0}^{1} q_{m} d m$ denotes the aggregate amount of initially allocated quotas and $\Delta Q$ is net government supply in the quota market.

Stochasticity in the quota price may originate both on the demand and supply side. On the supply side, the emissions target may be uncertain ex ante; alternatively, there may be uncertainty (due to imperfect observation) about the initial quota allocation (this would seem to be a relevant characterisation of the early days of the EU ETS). On the demand side, there may be uncertainty about demand for the final good, the number of firms (due to entry and exit), production of the pollutant, as well as costs. 
Our analysis is based on the assumption that firms face risk through prices only; risk is therefore fully extraneous. This is also true with endogenous quota price when uncertainty originates from the supply side, that is from government policy. Demand side uncertainty may also give rise to extraneous risk, such as in the case of stochastic entry and exit of firms (c.f. Baldursson and von der Fehr, 2004a). Our analysis is then still valid with endogenous quota price.

When risk originates from the demand side, however, firms are also likely to be subject to idiosyncratic, or firm-specific, risk. Effects resulting from price uncertainty will still be present with idiosyncratic risk. Baldursson and von der Fehr (2004a) demonstrate that qualitatively similar results may be obtained in this setting under certain technical conditions. More generally, results will depend on the interaction between aggregate and idiosyncratic shocks and their relative magnitudes.

\section{Tax Regime}

Rather than regulating emissions by a regime of tradable quotas the authorities may choose to regulate by tax on emissions. In this section we compare outcomes under such a system to those analysed above. We limit attention to the case of extraneous risk.

With a linear tax, $t$, on emissions firm profits are given by

$$
\pi=p x-c(x, a, y, k)-t[\rho(x)-a-k] .
$$

We retain the assumption that output, $x$, and abatement, $a$, are determined after uncertainty is resolved. First-order conditions for maximising profits at Stage 4 are

$$
\begin{aligned}
c_{x}+t \rho^{\prime} & =p, \\
c_{a} & =t,
\end{aligned}
$$

and first-order conditions at Stage 2 are

$$
\begin{aligned}
E\left[U^{\prime} c_{y}\right] & =0, \\
E\left[U^{\prime}\left[t-c_{k}\right]\right] & =0 .
\end{aligned}
$$

First assume the tax is fixed. Then, since $c_{y}$ and $c_{k}$ are deterministic, firms are not subject to any risk and the outcome is the same as in the riskneutral benchmark, where $c_{y}=0$ and $c_{k}=t$, in clear distinction from the quota regime. 
Consider next the case in which the tax rate is uncertain, ex ante, and only determined after investment decisions have been made. This case may be analysed in an analogous way as that of uncertain quota price with the restriction that $q \equiv 0 .{ }^{11}$ The comparison between tax and quota regimes now depends on the distribution of the tax rate and quota price, respectively. If the underlying uncertainty is due to unpredictable policy changes, due, for example, to arrival of new information or changes in political attitudes or regimes, ${ }^{12}$ then it may perhaps be reasonable to assume that these distributions are similar.

The comparison between the two types of regimes is therefore dependent on the origin of uncertainty: if the market itself gives rise to uncertainty then outcomes under the two regimes are different; if it is policy that is the source of uncertainty then outcomes may be similar. ${ }^{13}$

\section{Conclusion}

Market-based environmental regulation may expose market participants to considerable risk, as demonstrated by the experience of the European Emissions Trading System. Such risk is not only related to the emissions instrument as such, but may also be transmitted through induced changes in other, related markets. The purpose of this paper is to analyse how decisions on output and cleaning activities are affected by such types of risk.

By so doing, we have dealt with one of the limitations of our previous work (Baldursson and von der Fehr, 2004a) where we analysed risk arising from market-based environmental instruments without taking account of the production side of firms' activities. It turns out that endogenising output decisions does not qualitatively change our previous results. However, the product market effect mitigates risk exposure for 'dirty' firms but exacerbates risk for 'clean' firms (or dirty firms who have been allocated many quotas). As such, risk arising from environmental instruments has less of an impact on cleaning activities at dirty firms than when the product market effect is not present while the opposite is true for relatively clean firms.

\footnotetext{
${ }^{11}$ The tax regime could be brought closer to the quota regime by imposing the tax on emissions over a certain threshold; see Pezzey (2003).

${ }^{12}$ Baldursson and von der Fehr (2007) study a model where governments with different environmental preferences alternate stochastically.

${ }^{13}$ Barradale (2008) argues that while uncertainty associated with the federal production tax credit (PTC) has affected investment in wind power plant in the US, alternative implementations of the policy to support renewable energy may have higher perceived reliability.
} 
By endogenising the production side we have also been able to study the effect of risk arising from regulation on firms' product decisions. We have found that the nature of this effect depends on whether firms are dirty or clean on average and at the margin, respectively. For example, both dirty and clean firms underinvest relative to a risk-neutral benchmark if they have few quotas. However, a dirty firm with sufficiently large quota holdings will overinvest.

From a policy point of view our results point to a grandfathering rule for initial quota allocation. In order to minimise exposure to risk and induce efficient investment decisions relatively clean firms should be allocated no quotas while relatively dirty firms should be allocated some quotas but not sufficient to cover emissions in all contingencies. Specifically, there exist quota allocations such that dirty firms choose either production capacity or cleaning facilities as if they were not averse to risk. In general, however, these allocations are different for each type of investment. There may therefore be a tradeoff between productive and environmental efficiency.

\section{References}

[1] Abel, Andrew B (1983), Optimal investment under uncertainty, American Economic Review, 73, 228-33.

[2] Adar, Z and J M Griffin (1976): Uncertainty and the choice of pollution control instruments, Journal of Environmental Economics and Management, 3, 178-88.

[3] Baldursson, Fridrik M and Nils-Henrik M von der Fehr (2004a): Price volatility and risk exposure: on market-based environmental policy instruments, Journal of Environmental Economics and Management, 48(1), 682-704.

[4] Baldursson, Fridrik M and Nils-Henrik M von der Fehr (2004b): Prices vs. quantities: the irrelevance of irreversibility, Scandinavian Journal of Economics, 106(4), 805-821.

[5] Baldursson, Fridrik M and Nils-Henrik M von der Fehr (2007): A whiter shade of pale: on the political economy of regulatory instruments, Journal of the European Economic Association, 5(1), 37-65.

[6] Baldursson, Fridrik M and Nils-Henrik M von der Fehr (2008): Prices vs quantities: public finance and the choice of regulatory instruments, European Economic Review, 52, 1242-1255. 
[7] Batra, Raveendra N and Aman Ullah (1974): Competitive firm and the theory of input demand under price uncertainty, The Journal of Political Economy, 82(3), 537-48.

[8] Baumol, William J and Wallace Oates (1988): The Theory of Environmental Policy, Second Edition, Cambridge: Cambridge University Press.

[9] Baron D.P. (1970): Price uncertainty, utility, and industry equilibrium in pure competition, International Economic Review, 11, 463-480.

[10] Barradale, Merrill Jones (2008): Impact of policy uncertainty on renewable energy investment: wind power and PTC, USAEE WP 08-003, University of California at Berkeley.

[11] Chao, Hung-po and Robert Wilson (1993): Option value of emission allowances, Journal of Regulatory Economics, 5, 233-49.

[12] Dixit, Avinash and Robert Pindyck (1994): Investment under Uncertainty, Princeton NJ: Princeton University Press.

[13] von der Fehr, Nils-Henrik (1993), Tradable emission rights and strategic interaction, Environmental and Resource Economics, 3, 129-151.

[14] Fishelson, G (1976): Emission control policies under uncertainty, Journal of Environmental Economics and Management, 3, 189-97.

[15] Goldberg, Victor P (1990): Aversion to risk aversion in the new institutional economics, Journal of Institutional and Theoretical Economics, 146, 216-22.

[16] Green, Richard (2008), Carbon tax or carbon permits: the impact on generators' risks, The Energy Journal, 69 (3), 67-89.

[17] Hartman, Richard (1972): The effects of price and cost uncertainty on investment, Journal of Economic Theory, 5, 258-66.

[18] Lerner, A P (1971): The 1971 report of the president's council of economic advisers: priorities and efficiency, American Economic Review, 61, 527-30.

[19] Magnusson, Gudmundur (1969): Production under Risk, Acta Universitatis Upsaliensis, Studia Oeconomica Upsaliensia, 2, Uppsala University. 
[20] Meyer, Margaret A (1984): Prices vs. Quantities with Risk Aversion and Bankruptcy, unpublished manuscript, Nuffield College.

[21] Montero, Juan-Pablo (2002): Prices vs. quantities with incomplete enforcement, Journal of Public Economics, 85(3), 435-454.

[22] Newbery, David M (2008): Climate change policy and its effect on market power in the gas market, Journal of the European Economic Association, 6 (4), 727-51.

[23] Nickell, Stephen J (1977): The influence of uncertainty on investment, The Economic Journal, 87, 47-70.

[24] Norstrøm, Carl J (1974), Optimal capital adjustment under uncertainty, Journal of Economic Theory, 8, 139-48.

[25] Ogden, Joseph P, Frank C Jen and Philip F O'Connor (2002): Advanced Corporate Finance - Policies and Strategies, Upper Saddle River NJ: Prentice Hall.

[26] Pezzey, John (2003): Emission Taxes and Tradeable Permits: A Comparison of Views on Long-Run Efficiency, Environmental and Resource Economics 26, 329-342.

[27] Pindyck, Robert S (1982): Adjustment costs, uncertainty and the behavior of the firm, The American Economic Review, 72(3), 415-27.

[28] Roberts, Marc J and Michael Spence (1976): Effluent charges and licences under uncertainty, Journal of Public Economics, 5, 193-208.

[29] Sandmo, Agnar (1971): On the theory of the competitive firm under uncertainty, American Economic Review, 61, 65-73.

[30] Schmalensee, Richard, Paul L Joskow, Denny Ellerman, A, Montero, Juan Pablo and Bailey, Elizabeth (1998): An interrim evaluation of Sulfur Dioxide Emissions Trading, Journal of Economic Perspectives, $12,53-68$.

[31] Stavins, Robert N (1996): Correlated uncertainty and policy instrument choice, Journal of Environmental Economics and Management, 30, 21832 .

[32] Upton, C W (1971): The Allocation of Pollution Rights, University of Chicago, Urban Economics Report No 59. 
[33] Varian, Hal (1990): The role of risk aversion in economic modelling, Journal of Institutional and Theoretical Economics, 146, 223-5.

[34] Viaene, Jean-Marie and Itzhak Zilcha (1998): The behavior of competitive exporting firms under multiple uncertainty, International Economic Review, 39(3), 591-609.

[35] Weitzman, Martin L (1974): Prices vs. quantities, Review of Economic Studies, 41, 477-91.

[36] Xepapadeas, Anastasios (1999): Environmental policy and firm behavior: abatement investment and location decisions under uncertainty and irreversibility, NBER Technical Working Papers 0243, National Bureau of Economic Research, Inc.

[37] Yohe, Gary W (1977): Comparison of price and quantity controls: a survey, Journal of Comparative Economics, 1, 213-234.

[38] Yohe, Gary W (1978): Towards a general comparison of price controls and quantity controls under uncertainty, Review of Economic Studies, 45, 229-238.

[39] Zhao, Jinhua (2003): Irreversible abatement investment under cost uncertainties: tradable emission permits and emissions charges, Journal of Public Economics, 87, 2765-2789. 